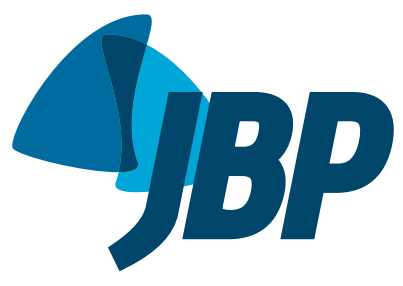

\title{
Impact of thoracic radiotherapy on respiratory function and exercise capacity in patients with breast cancer
}

\author{
Milena Mako Suesada ${ }^{1, a}$, Heloisa de Andrade Carvalho ${ }^{2, b}$, \\ André Luis Pereira de Albuquerque ${ }^{1, c}$, João Marcos Salge ${ }^{1, d}$, \\ Silvia Radwanski Stuart ${ }^{2, e}$, Teresa Yae Takagaki ${ }^{1, f}$
}

1. Divisão de Pneumologia, Instituto do Coração - InCor - Hospital das Clínicas, Faculdade de Medicina, Universidade de São Paulo, São Paulo (SP) Brasil.

2. Departamento de Radiologia e Oncologia / Radioterapia, Instituto de Radiologia - InRad -Faculdade de Medicina, Universidade de São Paulo São Paulo (SP) Brasil.

a. (ID) http://orcid.org/0000-0002-7665-9704

b. iD http://orcid.org/0000-0003-0979-7768

c. (iD $h t t p: / / o r c i d . o r g / 0000-0003-3486-5240$

d. (iD http://orcid.org/0000-0001-5121-0129

e. (iD http://orcid.org/0000-0002-0504-776X

f. (iD) http://orcid.org/0000-0003-2277-2100

Submitted: 9 May 2017.

Accepted: 13 February 2018.

Study carried out in the Departamento de Radiologia e Oncologia / Radioterapia, Instituto de Radiologia - InRad -

Faculdade de Medicina, Universidade de São Paulo, São Paulo (SP) Brasil.

\begin{abstract}
Objective: To evaluate the impact of thoracic radiotherapy on respiratory function and exercise capacity in patients with breast cancer. Methods: Breast cancer patients in whom thoracic radiotherapy was indicated after surgical treatment and chemotherapy were submitted to HRCT, respiratory evaluation, and exercise capacity evaluation before radiotherapy and at three months after treatment completion. Respiratory muscle strength testing, measurement of chest wall mobility, and complete pulmonary function testing were performed for respiratory evaluation; cardiopulmonary exercise testing was performed to evaluate exercise capacity. The total radiotherapy dose was $50.4 \mathrm{~Gy}(1.8$ Gy/fraction) to the breast or chest wall, including supraclavicular lymph nodes (SCLN) or not. Dose-volume histograms were calculated for each patient with special attention to the ipsilateral lung volume receiving $25 \mathrm{~Gy}\left(\mathrm{~V}_{25}\right)$, in absolute and relative values, and mean lung dose. Results: The study comprised 37 patients. After radiotherapy, significant decreases were observed in respiratory muscle strength, chest wall mobility, exercise capacity, and pulmonary function test results $(p<0.05)$. DLCO was unchanged. HRCT showed changes related to radiotherapy in $87 \%$ of the patients, which was more evident in the patients submitted to SCLN irradiation. $\mathrm{V}_{25} \%$ significantly correlated with radiation pneumonitis. Conclusions: In our sample of patients with breast cancer, thoracic radiotherapy seemed to have caused significant losses in respiratory and exercise capacity, probably due to chest wall restriction; SCLN irradiation represented an additional risk factor for the development of radiation pneumonitis.
\end{abstract}

Keywords: Breast neoplasms; Radiotherapy; Radiation pneumonitis; Respiratory function tests; Exercise test.

\section{INTRODUCTION}

In breast cancer, postoperative thoracic radiotherapy is widely used in order to reduce the risks of loco-regional recurrence and to improve overall survival. ${ }^{(1,2)}$ However, irradiation of thoracic structures involves risks, primarily to the lungs.

Radiation pneumonitis (RP) is the most significant adverse effect and generally appears between one and four months after radiotherapy completion. ${ }^{(3,4)}$ The etiology and physiopathology of RP are related to a cytokine-mediated signal cascade that causes early damage of the cells in the alveolar space, progressing to an acute exudative inflammatory process. Clinical symptoms include cough, low-grade fever, dyspnea, fatigue, and pleuritic chest pain. ${ }^{(3-5)}$ These symptoms can be reflected by changes on pulmonary function tests (PFTs) results, with reduced FVC, FEV ${ }_{1}, \mathrm{TLC}_{\text {, and }}$ DLCO. ${ }^{(3,4)}$ Radiologic evaluation of the lung toxicity has usually been made by chest X-rays. However, HRCT has proven to be sensitive in detecting early changes, but it is not used as part of routine follow-up. $(6,7)$
Radiotherapy-induced injury may also acutely lead to systemic impairment, frequently referred to as a diminished exercise capacity and worsening of quality of life. ${ }^{(8-10)}$ Those changes have been evaluated by means of specific questionnaires, but the objective quantification of such changes, to our knowledge, has not been previously performed. In breast cancer, this should be carefully considered due to improvement of prognosis and life expectancy in these patients. Therefore, it is essential to quantify and investigate exercise limitation after thoracic radiotherapy in order to identify the involved mechanisms.

The purpose of the present study, therefore, was to quantify the acute impact of thoracic radiotherapy on respiratory function and exercise capacity in patients with breast cancer at three months after irradiation.

\section{METHODS}

The study was approved by the institutional research ethics committee, and giving informed consent was mandatory for enrollment. Inclusion criteria were confirmed histological diagnosis of breast cancer, indication 
for postoperative irradiation, in accordance with the institutional routine protocol, and a period of at least four weeks with no treatment before radiotherapy was required. All of the patients had to be fully treated in the institution and were consecutively selected over a one-year period. Patients were excluded if they presented with metastatic disease, concomitant respiratory disease, neuromuscular or rheumatologic disease, or cognitive disorders hindering the completion of PFTs or exercise tests. The patients underwent HRCT of the chest, complete PFT, cardiopulmonary exercise testing (CPET), respiratory muscle strength testing, and measurement of chest wall mobility. In addition, the Medical Research Council (MRC) dyspnea scale was also applied to evaluate respiratory symptoms during activities of daily living over the study period. ${ }^{(11)}$

All of the measurements were conducted a few days (an average of 2 to 5 days) prior to the beginning of radiotherapy and at three months after the completion of treatment.

\section{Radiotherapy}

Radiotherapy was delivered using a 3D conformal technique. The whole breast or chest wall was irradiated with opposed tangential fields and, when indicated, additional irradiation of supraclavicular lymph nodes (SCLNs) was performed with a direct anterior field. Patients were treated with $6 \mathrm{MV}$ photon beams and a total dose of $50.4 \mathrm{~Gy}(28 \times 1.8 \mathrm{~Gy} ; 5$ days/week $)$. Dose-volume histograms for the heart, lungs, and contralateral breast were calculated with no tissue heterogeneity correction (Eclipse planning system; Varian $^{\circledR}$, Palo Alto, CA, USA). The ipsilateral lung volume that received at least $50 \%$ of the dose ( $25 \mathrm{~Gy}=\mathrm{V}_{25}$ ), corresponding to the limits of the fields (or the actual irradiated lung volume) and the mean lung dose were correlated with the functional test results. $\mathrm{V}_{25}$ was calculated as absolute $\left(\mathrm{cm}^{3}\right)$ and relative (\%) values.

\section{Respiratory function evaluation}

Complete PFTs and DLCO were performed with a body plethysmograph (Elite DX; MedGraphics Corp., Saint Paul, MN, USA). The following parameters were measured: FVC, $\mathrm{FEV}_{1}$, inspiratory capacity (IC), TLC, RV, maximal voluntary ventilation, and DLCO. Measurements were expressed as absolute volumes and percentages of the predicted values for the Brazilian population ${ }^{(12-14)}$ and performed according to the guidelines of the American Thoracic Society (ATS)/ European Respiratory Society. ${ }^{(15)}$

Respiratory muscle strength was assessed by MIP and MEP in accordance with the ATS guidelines. ${ }^{(16)}$ These variables were measured by using a pressure transducer (OEM Medical, Marshalltown, IA, USA).

Chest cirtometry was used in order to evaluate chest wall mobility at the level of axillary level and at the level of the xiphoid process. ${ }^{(17)}$ Patients were asked to exhale up to RV and then inhale up to TLC, and the difference between the two measurements was calculated.

\section{Exercise capacity evaluation}

A maximal incremental cycle ergometer protocol was conducted in accordance with the ATS recommendations ${ }^{(18)}$ using a CardiO $_{2}$ System ${ }^{\circledR}$ (MedGraphics). The following parameters were determined: oxygen uptake $\left(\mathrm{VO}_{2} ; \mathrm{mL} \cdot \mathrm{min}^{-1}\right)$; carbon dioxide output $\left(\mathrm{VCO}_{2} ; \mathrm{mL} \cdot \mathrm{min}^{-1}\right)$; respiratory exchange ratio; minute ventilation $\left(\mathrm{V}_{E^{\prime}} \mathrm{L} \cdot \mathrm{min}^{-1}\right)$; tidal volume $\left(\mathrm{V}_{T}, \mathrm{~mL}\right)$; and $\mathrm{RR}$ (breaths/min). The mean $\mathrm{VO}_{2}$ for the last 15 seconds of the ramp was considered as the peak oxygen uptake $\left(\mathrm{VO}_{2 \text { eak }}\right)$. During the test, 12-lead electrocardiography, blood pressure, and pulse oximetry values were monitored. In addition, dyspnea and leg fatigue were assessed by the modified Borg scale every two minutes. ${ }^{(19)}$

Dynamic relationships were determined to evaluate metabolic $\left(\Delta \mathrm{VO}_{2} / \Delta\right.$ workload $\left.[\mathrm{W}] ; \mathrm{mL} \cdot \mathrm{min}^{-1} \cdot \mathrm{W}^{-1}\right)$, cardiovascular $\left(\Delta \mathrm{HR} / \Delta \mathrm{VO}_{2} ;\right.$ beats $\left.\cdot \mathrm{min}^{-1} \cdot \mathrm{L} \cdot \mathrm{min}^{-1}\right)$, and respiratory $\left(\Delta \mathrm{V}_{\mathrm{E}} / \Delta \mathrm{VCO}_{2} ; \mathrm{L} \cdot \mathrm{min}^{-1} \cdot \mathrm{L} \cdot \mathrm{min}^{-1}\right)$ responses, as previously described. ${ }^{(20)}$ Ventilatory reserve was calculated using the $\mathrm{V}_{\mathrm{E}}$ at exercise cessation/maximal voluntary ventilation ratio as a reference.

\section{HRCT}

HRCT was performed with 1-mm slices at increments of $10 \mathrm{~mm}$ from the apex to the base of the lungs during maximal inspiration without the use of i.v. contrast. The scans were analyzed and scored in accordance with the Schratter-Sehn et al. scoring system. ${ }^{(6)}$ Briefly, this score ranges from zero (no changes) to 5 according to the severity of radiological abnormalities. A single radiologist, specializing in lung diseases, evaluated and classified all of the scans in accordance with the protocol.

\section{Classification of RP and radiation dermatitis}

RP was graded in accordance with the toxicity criteria by Cox et al., ${ }^{(21)}$ and radiation dermatitis was classified in accordance with the criteria for skin adverse events described by Freedman et al.(22) The two systems are based on the severity of respiratory and dermatological symptoms after radiotherapy, respectively.

\section{Statistical analysis}

The analyses of variations between the respiratory and exercise test results obtained before and after radiotherapy were performed using the Student's t-test. ANOVA was used in order to analyze the variance in HRCT scan results, in severity of RP, and in severity of radiation dermatitis in relation to changes in PFT and CPET variables after radiotherapy completion. The differences in changes observed in respiratory and exercise capacity variables between the group submitted to SCLN irradiation and that submitted to chest wall/breast radiotherapy only were analyzed with the Student's t-test. The differences in chest wall mobility and inspiratory muscle strength between the patients submitted to mastectomy and those submitted to sectorectomy were analyzed by the Student's t-test 
for independent samples. The significance level was set at $5 \%(p \leq 0.05)$. Statistical analysis of the data was performed with the IBM SPSS Statistics software package, version 20.0 (IBM Corporation, Armonk, NY, USA).

\section{RESULTS}

The study comprised 40 female patients; of those, 2 were excluded because they developed pleural metastasis, and 1 was excluded because she missed the third-month evaluation. Therefore, the final sample comprised 37 patients. The mean age of the study population was $53.5 \pm 10.9$ years. Seven patients (18.9\%) had a smoking history, but only 1 was a current smoker during the study period. No significant changes in the mean body mass index were observed between the two time points studied, that is, before radiotherapy and at three months after radiotherapy $\left(28.2 \pm 4.4 \mathrm{~kg} / \mathrm{m}^{2}\right.$ vs. $\left.28.2 \pm 4.8 \mathrm{~kg} / \mathrm{m}^{2}\right)$. Table 1 presents the affected breasts and the characteristics of treatment prior to radiotherapy. The mean time between chemotherapy and radiotherapy was 107.0 \pm 81.8 days. SCLNs were irradiated in 20 (54\%) of the cases. At three months after radiotherapy, 29 (78\%) of the patients had developed RP and 33 (89\%) presented with skin toxicity according to the adopted scales (Table 2). Worsening of respiratory symptoms was also observed according to MRC scale. Before radiotherapy, $30(81.2 \%)$ of the patients reported no symptoms (zero score), and $7(18.9 \%)$ had a score of 1 . After radiotherapy, the number of patients with no symptoms decreased to $8(21.6 \%), 24(64.9 \%)$ had a score of 1 , and $5(13.5 \%)$ had a score of 2 .

Table 3 shows a comparison of mean lung dose (MLD) and $V_{25}$ (in absolute and relative values) between patients who underwent SCLN irradiation or and those who did not. Only $\mathrm{V}_{25} \%$ showed a significant difference between the two groups of patients.

At 3 months after radiotherapy, we found that there was a significant loss in MIP and MEP ( $p<0.0001$ for both), as well as significant decreases in all chest wall mobility at the axillary level and at the level of the xiphoid process $(p<0.0001)$. Regarding PFTs, except for DLCO, a significant decrease in FVC, FEV TLC, and IC was detected after radiotherapy (Table 4).

Maximal CPET results showed that there was a significant decrease in workload and $\mathrm{VO}_{2 \text { peak }}$ after radiotherapy $(p<0.05)$. Significant reductions were also detected in $\mathrm{V}_{E^{\prime}}, \mathrm{V}_{T^{\prime}}$ and respiratory exchange ratio but not in RR (Table 4). All of those changes were observed only at peak exercise.

The dynamic relationships showed significant changes in metabolic response, and there was a tendency toward a decrease in the respiratory response when compared with the pre-radiotherapy condition (Table 4). All of the patients used an average of $40 \%$ of ventilatory reserve at peak exercise before and after radiotherapy.

All of the respiratory parameters, as well as those obtained from exercise testing, showed to be decreased when patients submitted to SCLN irradiation were included; however, the only significant decrease was found for chest wall mobility at the level of the xiphoid process ( $p=0.03$; Table 3 ).

After radiotherapy, changes were identified in $87 \%$ of the HRCT scans (Figure 1), and the distribution according to the adopted scoring system ${ }^{(6)}$ is presented in Table 5. Those changes were more prominent in the patients submitted to SCLN irradiation.

Higher HRCT scores were significantly correlated with greater losses of FVC $(p=0.01)$. None of the patients had grade 3 or higher radiation dermatitis, and the presence of skin symptoms was significantly correlated with reductions in chest wall mobility at the level of the xiphoid process $(p=0.05)$.

Patients submitted to mastectomy showed greater losses in chest wall mobility when compared with the other patients $(p=0.06)$. Grade 2 radiation dermatitis was more prevalent in the former group of patients ( $51 \%$ vs. $33 \%$ in those submitted to breast conserving surgery).

\section{DISCUSSION}

The present study reports the results of a prospective analysis of the early effects of thoracic radiotherapy on respiratory function at rest and during exercise in patients treated for breast cancer. Changes in PFT results and radiological findings after irradiation in

Table 1. Affected breast and delivered treatments prior to radiotherapy in the study sample $(\mathrm{N}=37)$.

\begin{tabular}{lc} 
Parameter & Patient, $\mathbf{n}(\%)$ \\
Side of the disease & \\
Right & $22(59.5)$ \\
Left & $14(37.8)$ \\
Bilateral & $1(2.7)$ \\
Surgery & \\
Mastectomy & $22(59.5)$ \\
Sectorectomy & $15(40.5)$ \\
Chemotherapy & $30(81.1)$ \\
AC & $10(33.3)$ \\
Taxol & $3(10.0)$ \\
AC + taxol & $13(43.3)$ \\
FAC & $3(10.0)$ \\
CMF & $1(3.3)$ \\
Hormone therapy & $23(62.1)$ \\
Tamoxifen & $14(37.8)$ \\
Other & $9(24.3)$ \\
\hline
\end{tabular}

AC: adriamycin + cyclophosphamide; FAC: fluorouracil + doxorubicin + cyclophosphamide; and CMF: cyclophosphamide + methotrexate + fluorouracil.

Table 2. Incidence of radiation pneumonitis and radiation dermatitis at three months after radiotherapy in the study sample $(\mathrm{N}=37)$.

\begin{tabular}{cccc}
\hline Grade & $\mathbf{0}$ & $\mathbf{1}$ & $\mathbf{2}$ \\
Radiation pneumonitis & 8 & 19 & 10 \\
& $(21.6 \%)$ & $(51.3 \%)$ & $(27.1 \%)$ \\
Radiation dermatitis & 4 & 16 & 17 \\
& $(10.8 \%)$ & $(43.3 \%)$ & $(45.9 \%)$ \\
\hline
\end{tabular}


Table 3. Comparisons of dosimetric values, as well as of respiratory and exercise test results, between patients who underwent supraclavicular lymph node irradiation and those who did not.

\begin{tabular}{|c|c|c|c|}
\hline \multirow[t]{2}{*}{ Variable } & \multicolumn{2}{|c|}{ SCLN irradiation } & \multirow[t]{2}{*}{$\mathbf{p}$} \\
\hline & No & Yes & \\
\hline \multicolumn{4}{|l|}{ Dosimetric value } \\
\hline Mean lung dose, cGy & $539.2 \pm 168.1$ & $738.5 \pm 339.5$ & 0.10 \\
\hline $\mathrm{V}_{25}, \mathrm{~cm}^{3}$ & $114.6 \pm 53$ & $203.9 \pm 127.8$ & 0.10 \\
\hline $\mathrm{V}_{25} \%$ & $6.9 \pm 3.0$ & $11.7 \pm 6.4$ & 0.04 \\
\hline \multicolumn{4}{|l|}{ Respiratory and exercise test } \\
\hline \multicolumn{4}{|l|}{ Muscle strength, $\mathrm{CmH}_{2} \mathrm{O}$} \\
\hline$\Sigma$ MIP & $25.0 \pm 16.3$ & $24.7 \pm 14.6$ & 0.98 \\
\hline$\Sigma$ MEP & $15.5 \pm 15.1$ & $22.6 \pm 16.5$ & 0.27 \\
\hline \multicolumn{4}{|l|}{ Chest wall mobility, cm } \\
\hline$\Sigma$ Axillary & $1.3 \pm 1.0$ & $1.7 \pm 0.8$ & 0.21 \\
\hline$\Sigma$ Xiphoid & $1.0 \pm 1.4$ & $1.9 \pm 1.2$ & 0.03 \\
\hline \multicolumn{4}{|l|}{ Pulmonary function test } \\
\hline$\Sigma F V C, L$ & $0.14 \pm 0.22$ & $0.23 \pm 0.23$ & 0.13 \\
\hline$\Sigma \mathrm{FEV}_{1}, \mathrm{~L}$ & $0.11 \pm 0.2$ & $0.16 \pm 0.17$ & 0.19 \\
\hline \multicolumn{4}{|l|}{ Exercise test } \\
\hline$\Sigma$ Workload, Watts & $4.2 \pm 1.49$ & $17.4 \pm 22.0$ & 0.21 \\
\hline $\mathrm{VO}_{2 \text { peak }}, \mathrm{mL} / \mathrm{kg} / \mathrm{min}$ & $0.96 \pm 3.0$ & $0.98 \pm 2.1$ & 0.98 \\
\hline
\end{tabular}

SCLN: supraclavicular lymph node; $\mathrm{V}_{25}$ : ipsilateral lung volume receiving $25 \mathrm{~Gy}$; and $\mathrm{VO}_{2 \text { peak }}$ : oxygen uptake at peak exercise.

Table 4. Variation in respiratory muscle strength, chest wall mobility, pulmonary function testing, and cardiopulmonary exercise testing before and after three months of radiotherapy.

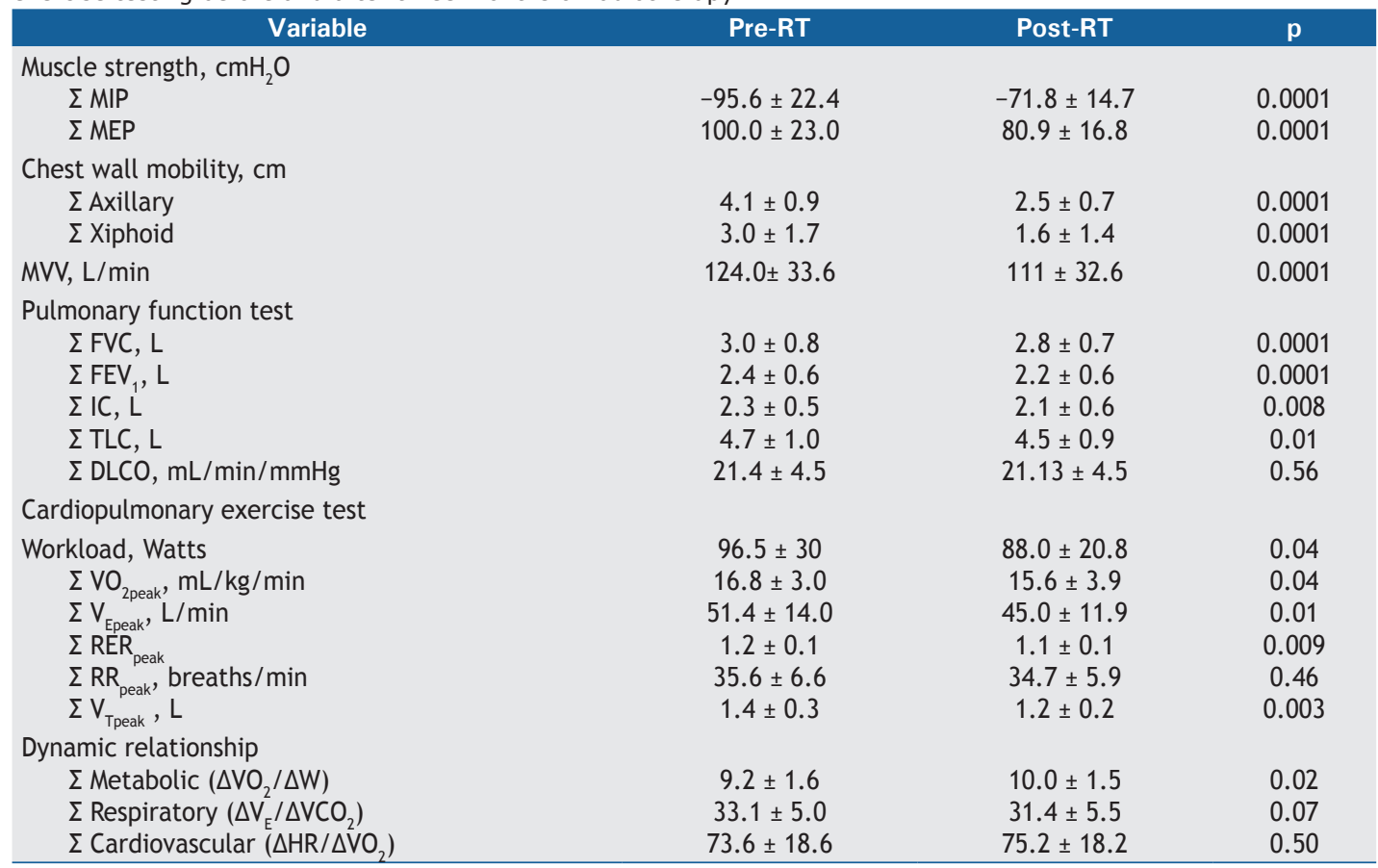

RT: radiotherapy; $\mathrm{MVV}$ : maximal voluntary ventilation; IC: inspiratory capacity; $\mathrm{VO}_{2 \text { peak }}$ : oxygen uptake at peak exercise; $V_{\text {ppeak }}$ : minute ventilation at peak exercise; $R_{E R}$ peak : respiratory exchange ratio at peak exercise; and $\triangle \mathrm{VCO}_{2}$ : carbon dioxide output.

breast cancer patients have been described in previous studies. ${ }^{(3,4,5,7)}$ In our study, irradiation has led to negative effects on exercise capacity, respiratory muscle strength, and chest wall mobility. To our knowledge, these findings have never been published and reveal a physiological approach to cancer-related fatigue, present in more than $30 \%$ of breast cancer patients at the completion of therapy. ${ }^{(23)}$ Those symptoms may limit activities of daily living and enhance muscle atrophy, contributing to impairment of physical performance. The reported incidence of RP in breast cancer patients submitted to radiotherapy varies from $4.5 \%$ to $80 \%$ in prospective studies, ${ }^{(24-29)}$ and these results are related to the irradiated lung volumes, ${ }^{(25,26)} \mathrm{MLD}_{,}{ }^{(6,27)} \mathrm{age}_{{ }^{(4)}}$ performance status, ${ }^{(28)}$ use of chemotherapy, ${ }^{(27)}$ and use of tamoxifen. ${ }^{(29)}$ In the present study, we observed 

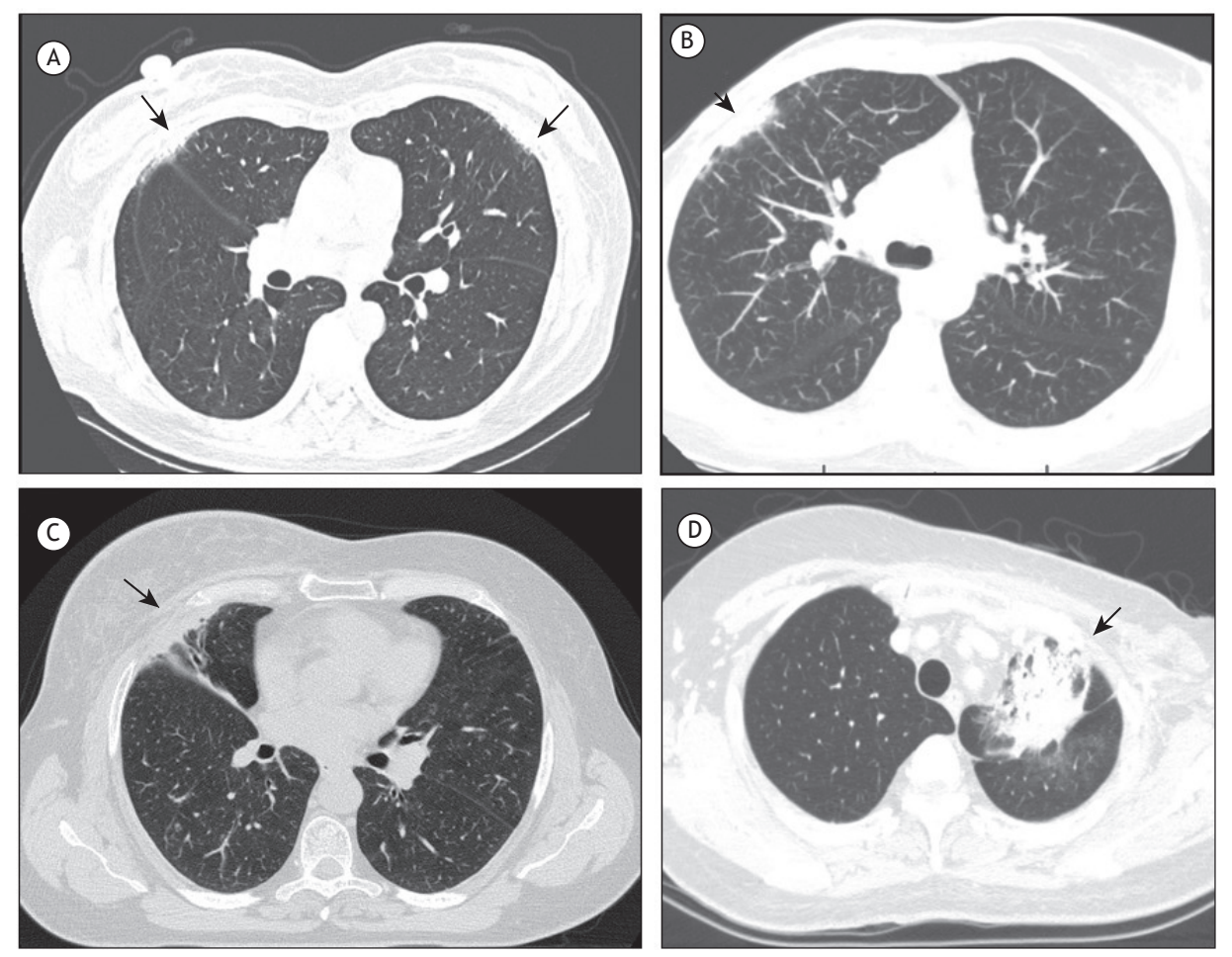

Figure 1. HRCT scans showing features of radiation pneumonitis. In A, HRCT scan scored as 1 in a patient submitted to bilateral treatment. In, B, C, and D, respectively, HRCT scans scored as 2,3 , and 5 ..

Table 5. Classification of HRCT scans after radiotherapy in the overall study population $(\mathrm{N}=37)$, as well as in patients who underwent supraclavicular lymph node irradiation and those who did not, according to the scoring system by Schratter-Sehn et al. ${ }^{(6), a}$

\begin{tabular}{|c|c|c|c|}
\hline \multirow[t]{2}{*}{ HRCT scan score } & \multirow[t]{2}{*}{ Overall } & \multicolumn{2}{|c|}{ SCLN irradiation } \\
\hline & & $\begin{array}{c}\text { No } \\
(n=17)\end{array}$ & $\begin{array}{c}\text { Yes } \\
(n=20)\end{array}$ \\
\hline 0 & $5(13.5 \%)$ & $3(17.7 \%)$ & $2(10 \%)$ \\
\hline 1 & $17(45.9 \%)$ & $9(52.9 \%)$ & $8(40 \%)$ \\
\hline 2 & $8(21.6 \%)$ & $3(17.6 \%)$ & $5(25 \%)$ \\
\hline 3 & $5(13.5 \%)$ & $2(11.8 \%)$ & $3(15 \%)$ \\
\hline 4 & $0(0.0 \%)$ & $0(0.0 \%)$ & $0(0.0 \%)$ \\
\hline 5 & $2(5.4 \%)$ & $0(0.0 \%)$ & $2(10 \%)$ \\
\hline
\end{tabular}

SCLN: supraclavicular lymph node. aScore: 0 = no changes; 1 = septal thickening, reticular subpleural opacities; 2 = subpleural thickening $>2 \mathrm{~cm}$ parallel to the chest wall; $3=$ parenchymal bands $\geq 2.5 \mathrm{~cm}$ from the lung toward the pleural surface; $4=$ honeycombing aspect, cystic areas ( $>1 \mathrm{~cm}$ diameter), thickened walls; $5=$ ground glass opacities, acute radiological changes.

a $78 \%$ incidence of RP, $51 \%$ and $27 \%$ being classified as grade 1 and grade 2, respectively. The incidence of $\mathrm{RP}$ in the present study correlated with the MRC scale results, reinforcing that the severity of respiratory symptoms correlated with decreased activities of daily living and exercise tolerance.

The majority of the patients $(81 \%)$ included in the present study had been previously treated with chemotherapy, which prevents the analysis of differences between patients treated with chemotherapy and those who were not. Chemotherapy by itself may cause pulmonary toxicity, among other side effects. Therefore, a higher risk of RP might be present when chemotherapy is associated with radiotherapy. ${ }^{(30)}$
We found that the patients who used tamoxifen prior to radiotherapy $(61 \%)$ showed more relevant losses in chest wall mobility than those who did not use it. However, changes in muscle strength and pulmonary function parameters were similar in both groups.

In the present study, the high incidence of radiation dermatitis (grade 1, in $43 \%$ of the patients; and grade 2, in $46 \%$ ) corroborates other studies. ${ }^{(22,31)}$ Both radiation dermatitis grades and treatment with SCLN irradiation were significantly correlated with the decrease in chest wall mobility at the level of the xiphoid process. These results strongly suggest that the loss of chest wall mobility might be associated with the severity of skin toxicity and SCLN irradiation. However, these 
findings might not only be related to SCLN irradiation but also to the fact that patients with more advanced tumors had been submitted to mastectomy or to more extended axillary surgery, and, consequently, SCLN irradiation had been prescribed.

Dunlap et al. ${ }^{(32)}$ suggested that chest wall toxicity might affect muscles, connective tissue, neurovascular bundle, and bones. In addition, Kinsella et al. ${ }^{(33)}$ showed that doses over $60 \mathrm{~Gy}$ correlated with symptoms of nerve dysfunction, including paresthesia, weakness, and pain. Those studies reinforce the hypothesis that radiotherapy for breast cancer treatment might ultimately engender chest wall restriction, which would diminish the ability of muscles to contract and generate power, eventually leading to muscle weakness. Our patients had decreases in MIP and MEP, which could be also found in pulmonary function impairment. Inspiratory muscle weakness affects the maximal IC effort, causing reductions in TLC and IC. Conversely, expiratory muscle weakness affects the maximal expiratory effort, leading to an increase in RV.

A few studies $(3,4,7)$ have demonstrated gas exchange, $\mathrm{PFT}$, and radiological abnormalities due to irradiation of breast cancer. In the present study, DLCO was the only variable with no significant change, unlike in other studies in the literature. Erven et al. ${ }^{(34)}$ suggested that TLC was the most affected parameter and that that reduction was probably related to decreased parenchymal elasticity in the irradiated portion of the lung, which could be due to fibrosis and could explain further reductions in DLCO. Our results indicate that the reduction in TLC was probably related to changes in respiratory muscle strength and chest wall mobility. Furthermore, the HRCT scans showed a high incidence of parenchymal changes after radiotherapy; however, they were mostly confined to the pulmonary parenchyma near the pleural surface and chest wall-HRCT scan score of $1-2$ in $66 \%$ of the cases, and only $2(5.4 \%)$ of the patients presented with a score of 5 . The low incidence of severe parenchymal changes probably preserved DLCO in our patients, but this fact also limited the statistical power of the analysis of severe events.

As expected, the inclusion of the SCLN irradiation in the treatment was related to greater severity of RP and radiological changes. The loss of chest wall mobility at the level of the xiphoid process was also significantly higher in those patients. Once again, this finding might be confused with the type of surgery performed in more advanced cases.

Likewise, $V_{25} \%$ was significantly higher in patients submitted to SCLN irradiation treatment. $V_{25}$ has been previously described as a predictor of lung toxicity in a study of radiotherapy dose escalation for lung cancer. ${ }^{(35)}$ However, $\mathrm{V}_{20} \%$ values higher than $30 \%$ were also defined as causing a higher risk of RP, resulting in radiological and functional impairment. ${ }^{(36)}$ We have chosen $\mathrm{V}_{25}$ in order to correlate our results with lung volumes, which are included in the limits of the fields for radiotherapy in breast cancer patients. Only $\mathrm{V}_{25} \%$ correlated with functional/radiological impairment, in agreement with the already defined constraints that are related to the proportion of the irradiated lung volume that receives a certain dose. ${ }^{(37)}$ However, minimizing $V_{25}$ to $100 \mathrm{~cm}^{3}$ or less may also be a strategy to reduce pulmonary toxicity ${ }^{(4)}$ due to breast cancer irradiation. The MLD was not related to any abnormality, probably due to the small amount of lung tissue irradiated in breast cancer patients.

Few investigations have evaluated the exercise capacity as a predictor of RP. Miller et al. ${ }^{(38)}$ used the six-minute walk test in patients with lung cancer and found that good functional capacity and good PFT results prior to radiotherapy apparently reduced the risk of RP. In our study, CPET was chosen for this evaluation, because it allows a global assessment of integrative exercise responses. ${ }^{(18)}$ We observed a significant decrease in workload, in $\mathrm{VO}_{2 \text { peak }}$ in $\mathrm{V}_{\mathrm{E}}$ and in $\mathrm{V}_{\mathrm{T}}$ and respiratory exchange ratio at peak exercise.

Normally, $\mathrm{VO}_{2}$ increases almost at the same pace as does workload, and this relationship $\left(\Delta \mathrm{VO}_{2} / \Delta \mathrm{W}\right)$ reflects the efficiency of the metabolic component linked to skeletal muscles. $\mathrm{A}$ high $\Delta \mathrm{VO}_{2} / \Delta \mathrm{W}$ ratio after radiotherapy might reflect a great overload related to excessive work done by the ventilatory muscles, restricted chest wall mobility, and reduced expansion of $\mathrm{V}_{\mathrm{T}}$ during exercise. Lower ventilation and $\mathrm{V}_{\mathrm{T}}$ reinforce chest wall restriction after the intervention, which is in line with the lower cirtometry and lung volume results found in our study. Despite this possible overload of ventilatory muscles, a definitive ventilatory limitation was not found. Finally, we cannot rule out an additional component of peripheral muscle limitation, since maximal $\mathrm{VO}_{2}$ was reduced and leg fatigue by the modified Borg scale was increased after radiotherapy.

Decreased exercise performance, with no ventilatory or cardiovascular limitation, indicates that our patients presented lower exercise tolerance at three months after radiotherapy. These findings reinforce our qualitative MRC scale results and could be part of the so-called cancer-related fatigue(39-41); however, further studies are needed to improve the determination of the mechanisms involved.

The fact that the present study was designed to evaluate the early effects of radiation may represent a limitation, because these effects may or may not be reversible. Late reactions are expected to be present at least six months after the end of the treatment and may be reflected as fibrosis, with or without symptoms or clinical manifestations. ${ }^{(5,34)}$ Therefore, a long-term follow-up period is needed to assess the outcome of these patients and the impact of our findings on their quality of life.

In conclusion, thoracic radiotherapy for breast cancer can acutely lead to significant impairment in functional capacity and exercise performance. The negative impact on the respiratory system was characterized by muscle weakness and restriction of chest wall mobility that could cause decreases in PFT results. There were significant decreases in maximal CPET results. $\mathrm{V}_{25} \%$ 
was correlated with a higher risk of RP. Finally, the inclusion of SCLN irradiation in the treatment fields represents a potential risk factor for the development of RP with functional repercussions.

\section{REFERENCES}

1. Overgaard M, Hansen PS, Overgaard J, Rose C, Andersson $M$, Bach $F$, et al. Postoperative radiotherapy in high-risk premenopausal women with breast cancer who receive adjuvant chemotherapy. Danish Breast Cancer Cooperative Group 82b Trial. N Engl J Med. 1997;337(14):949-55. https://doi.org/10.1056/ NEJM199710023371401

2. Minor GI, Yashar CM, Spanos WJ Jr, Jose BO, Silverman CL, Carrascosa $L A$, et al. The relationship of radiation pneumonitis to treated lung volume in breast conservation therapy. Breast $J$. 2006;12(1):48-52. https://doi.org/10.1111/j.1075-122X.2006.00180.x

3. Jaén J, Vázquez G, Alonso E, León A, Guerrero R, Almansa JF. Changes in pulmonary function after incidental lung irradiation for breast cancer: a prospective study. Int J Radiat Oncol Biol Phys. 2006;65(5):1381-8. https://doi.org/10.1016/j.jirobp.2006.03.008

4. Krengli M, Sacco M, Loi G, Masini L, Ferrante D, Gambaro G, et al Pulmonary changes after radiotherapy for conservative treatment of breast cancer: a prospective study. Int J Radiat Oncol Biol Phys. 2008;70(5):1460-7. https://doi.org/10.1016/j.jirobp.2007.08.050

5. Chopra RR, Bogart JA. Radiation therapy-related toxicity (including pneumonitis and fibrosis). Hematol Oncol Clin North Am. 2010;24(3):625-42. https://doi.org/10.1016/j.hoc.2010.03.009

6. Schratter-Sehn AU, Schurawitzki M, Zach M, Schratter M. Highresolution computed tomography of the lungs in irradiated breast cancer patients. Radiother Oncol. 1993;27(3):198-202. https://doi. org/10.1016/0167-8140(93)90074-I

7. Järvenpää R, Holli K, Pitkänen M, Hyödynmaa S, Rajala J, Lahtela SL, et al. Radiological pulmonary findings after breast cancer irradiation: a prospective study. Acta Oncol. 2006;45(1):16-22. https://doi. org/10.1080/02841860500334921

8. Whelan TJ, Levine M, Julian J, Kirkbride P, Skingley P. The effects of radiation therapy on quality of life of women with breast carcinoma: results of a randomized trial. Ontario Clinical Oncology Group. Cancer. 2000:88(10):2260-6. https://doi.org/10.1002/(SICI)10970142(20000515)88:10<2260::AID-CNCR9>3.0.CO;2-M

9. Markes M, Brockow T, Resch KL. Exercise for women receiving adjuvant therapy for breast cancer. Cochrane Database Syst Rev. 2006;18(4):CD005001. https://doi.org/10.1002/14651858. CD005001.pub2

10. Dimeo F, Schwartz S, Wesel N, Voigt A, Thiel E. Effects of an endurance and resistance exercise program on persistent cancerrelated fatigue after treatment. Ann Oncol. 2008;19(8):1495-9. https://doi.org/10.1093/annonc/mdn068

11. Kovelis D, Segretti NO, Probst VS, Lareau SC, Brunetto AF, Pitta F. Validation of the Modified Pulmonary Functional Status and Dyspnea Questionnaire and the Medical Research Council scale for use in Brazilian patients with chronic obstructive pulmonary disease. Bras Pneumol. 2008;34(12):1008-18. https://doi.org/10.1590/S180637132008001200005

12. Neder JA, Andreoni S, Castelo-Filho A, Nery LE. Reference values for lung function tests. I. Static volumes. Braz J Med Biol Res. 1999;32(6):703-17. https://doi.org/10.1590/S0100 879X1999000600006

13. Pereira CA, Sato T, Rodrigues SC. New reference values for forced spirometry in white adults in Brazil. J Bras Pneumol. 2007; 33(4):397406. https://doi.org/10.1590/S1806-37132007000400008

14. Neder JA, Andreoni S, Peres C, Nery LE. Reference values for lung function tests. III. Carbon monoxide diffusing capacity (transfe factor). Braz J Med Biol Res. 1999:32(6):729-37. https://doi. org/10.1590/S0100-879X1999000600008

15. Miller MR, Hankinson J, Brusasco V, Burgos F, Casaburi R, Coates A et al. Standardisation of spirometry. Eur Respir J. 2005;26(2):319-38. https://doi.org/10.1183/09031936.05.00034805

16. American Thoracic Society/European Respiratory Society. ATS/ERS Statement on respiratory muscle testing. Am J Respir Crit Care Med. 2002;166(4):518-624. https://doi.org/10.1164/rccm.166.4.518

17. Kakizaki F, Shibuya M, Yamazaki T, Yamada M, Suzuki H, Homma Preliminary Report of the Effects of Respiratory Muscle Stretch Gymnastics on Chest Wall Mobility in Patients With Chronic Obstructive Pulmonary Disease. J Cardiopulm Rehabil. 1999:19(6):3901. https://doi.org/10.1097/00008483-199911000-00015
18. American Thoracic Society/American College of Chest Physicians ATS/ACCP Statement on cardiopulmonary exercise testing. Am J Respir Crit Care Med. 2003;167(2):212-77.

19. O'Donnell DE. Breathlessness in patients with chronic airflow limitation. Mechanisms and management. Chest 1994;106(3):90412

20. Neder JA, Nery LE, Peres C Whipp BJ. Reference values for dynamic responses to incremental cycle ergometry in males and females aged 20 to 80. Am J Resp Crit Care Med. 2001:164(8 Pt 1):1481-6. https://doi.org/10.1164/ajrccm.164.8.2103007

21. Cox JD, Stetz J, Pajak TF. Toxicity criteria of the Radiation Therapy Oncology Group (RTOG) and the European Organization for Research and Treatment of Cancer (EORTC). Int J Radiat Oncol Biol Phys. 1995;31(5):1341-6. https://doi.org/10.1016/0360-3016(95)00060-C

22. Freedman GM, Li T, Nicolaou N, Chen Y, Ma CC, Anderson PR. Breast intensity-modulated radiation therapy reduces time spent with acute dermatitis for women of all breast sizes during radiation. Int $J$ Radiat Oncol Biol Phys. 2009;74(3):689-94. https://doi.org/10.1016/j. ijrobp.2008.08.071

23. Evans ES, Battaglini CL, Groff DG, Hackney AC. Aerobic exercise intensity in breast cancer patients: a preliminary investigation. Integr Cancer Ther. 2009;8(2):139-47. https://doi. org/10.1177/1534735409335506

24. Kubo A, Osaki K, Kawanaka T, Furutani S, Ikushima H, Nishitan $H$. Risk factors for radiation pneumonitis caused by whole breast irradiation following breast-conservative surgery. J Med Invest. 2009;56(3-4):99-110. https://doi.org/10.2152/jmi.56.99

25. Kahan Z, Csenki M, Varga Z, Szil E, Cserhati A, Balogh A, et al. The risk of early and late lung sequelae after conformal radiotherapy in breast cancer patients. Int J Radiat Oncol Biol Phys. 2007;68(3):673 81. https://doi.org/10.1016/j.jirobp.2006.12.016

26. Rancati T, Wennberg B, Lind P, Svane G, Gagliardi G. Early clinical and radiological pulmonary complications following breas cancer radiation therapy: NTCP fit with four different models. Radiother Oncol. 2007;82(3):308-16. https://doi.org/10.1016/j radonc.2006.12.001

27. Rodrigues G, Lock M, D'Souza D, Yu E, Dyk JV. Prediction of radiation pneumonitis by dose - volume histogram parameters in lung cancer--a systematic review. Radiother Oncol. 2004;71(2):12738. https://doi.org/10.1016/j.radonc.2004.02.015

28. Hernberg $M$, Virkkunen $P$, Maasilta $P$, Keyriläinen J, Blomqvist $C$ Bergh J, et al. Pulmonary toxicity after radiotherapy in primary breast cancer patients: results from a randomized chemotherapy study. Int J Radiat Oncol Biol Phys. 2002:52(1):128-36. https://doi.org/10.1016/ S0360-3016(01)01760-6

29. Azria D, Gourgou S, Sozzi WJ, Zouhair A, Mirimanoff RO, Kramar $A$, et al. Concomitant use of tamoxifen with radiotherapy enhances subcutaneous breast fibrosis in hypersensitive patients. Br J Cancer. 2004;91(7):1251-60. https://doi.org/10.1038/sj.bjc.6602146

30. Segawa Y, Takigawa N, Kataoka M Takata I, Fujimoto N, Ueoka H Risk factors for development of radiation pneumonitis following radiation therapy with or without chemotherapy for lung cancer. Int J Radiat Oncol Biol Phys. 1997;39(1): 91-8. https://doi.org/10.1016/ S0360-3016(97)00297-6

31. Osako T, Oguchi M, Kumada M, Nemoto $K$, Iwase T, Yamashita T. Acute radiation dermatitis and pneumonitis in Japanese breast cance patients with whole breast hypofractionated radiotherapy compared to conventional radiotherapy. Jpn J Clin Oncol. 2008:38(5):334-8. https://doi.org/10.1093/jjco/hyn030

32. Dunlap NE, Cai J, Biedermann GB, Yang W, Benedict SH, Sheng $\mathrm{K}$, et al. Chest wall volume receiving $>30 \mathrm{~Gy}$ predicts risk of severe pain and/or rib fracture after lung stereotactic body radiotherapy. Int $J$ Radiat Oncol Biol Phys. 2010;76(3):796-801. https://doi.org/10.1016/i. ijrobp.2009.02.027

33. Kinsella TJ Sindelar WF, Deluca AM, Pezeshkpour G, Smith $R$ Maher $\mathrm{M}$, et al. Tolerance of peripheral nerve to intraoperative radiotherapy (IORT): clinical and experimental studies. Int J Radia Oncol Biol Phys. 1985;11(9):1579-85. https://doi.org/10.1016/0360 3016(85)90209-3

34. Erven K, Weltens C, Nackaerts K, Fieuws S, Decramer M, Lievens 
Y. Changes in pulmonary function up to 10 years after locoregional breast irradiation. Int J Radiat Oncol Biol Phys. 2012;82(2):701-7. https://doi.org/10.1016/j.jijobp.2010.12.058

35. Armstrong JG, Zelefsky MJ, Leibel SA, Burman C, Han C, Harrison LB, et al. Strategy for dose escalation using 3-dimensional conformal radiation therapy for lung cancer. Ann Oncol. 1995;6(7):693-7. https:// doi.org/10.1093/oxfordjournals.annonc.a059286

36. Blom Goldman U, Anderson M, Wennberg B, Lind P. Radiation pneumonitis and pulmonary function with lung dose-volume constraints in breast cancer irradiation. J Radiother Pract 2014;13(2):211-217. https://doi.org/10.1017/S1460396913000228

37. Marks LB, Bentzen SM, Deasy JO, Kong FM, Bradley JD, Vogelius IS, et al. Radiation dose-volume effects in the lung. Int J Radiat Oncol Biol Phys. 2010;76(3 Suppl):S70-6. https://doi.org/10.1016/j. ijrobp.2009.06.091
38. Miller KL, Kocak Z, Kahn D, Zhou SM, Baydush A, Hollis D, et al. Preliminary report of the 6-minute walk test as a predictor of radiation-induced pulmonary toxicity. Int J Radiat Oncol Biol Phys. 2005;62(4):1009-13. https://doi.org/10.1016/j.jijobp.2004.12.054

39. Mock V, Pickett M, Ropka ME, Muscari Lin E, Stewart KJ, Rhodes $V A$, et al. Fatigue and quality of life outcomes of exercise during cancer treatment. Cancer Pract. 2001;9(3):119-27. https://doi. org/10.1046/.1523-5394.2001.009003119.x

40. Griffith K, Wenzel J, Shang J, Thompson C, Stewart K, Mock V. Impact of a walking intervention on cardiopulmonary fitness, self-reported physical function, and pain in patients undergoing treatment for solid tumors. Cancer 2009;115(20):4874-84. https:// doi.org/10.1002/cncr.24551

41. Ryan JL, Carroll JK, Ryan EP, Mustian KM, Fiscella K, Morrow GR. Mechanisms of cancer-related fatigue. Oncologist 2007;12 Suppl 1:22-34. https://doi.org/10.1634/theoncologist.12-S1-22. 